\title{
Atividade antimicrobiana do óleo essencial do alecrim associado ao hidróxido de cálcio
}

Antimicrobial activity of rosemary essential oil associated with calcium hydroxide

Actividad antimicrobiana del aceite esencial de romero asociado al hidróxido de calcio

Bianca Maria Beserra Costa ORCID: https://orcid.org/0000-0002-8132-9881 Universidade de Pernambuco, Brasil E-mail: bianca.bcosta@upe.br

Rayane Soares Silva ORCID: https://orcid.org/0000-0002-7556-5140 Universidade de Pernambuco, Brasil

E-mail: raay_soares@hotmail.com

Paulo Maurício Reis de Melo Júnior ORCID: https://orcid.org/0000-0001-9926-5348 Universidade de Pernambuco, Brasil E-mail: Paulo.reis@upe.br

Rosana Maria Coelho Travassos ORCID: https://orcid.org/0000-0003-4148-1288 Universidade de Pernambuco, Brasil E-mail: travassos.rosana@gmail.com

Sandra Maria Alves Sayão Maia ORCID: https://orcid.org/0000-0003-3172-2332

Universidade de Pernambuco, Brasil

E-mail: sandrinhasayao@hotmail.com

Luciano Barreto Silva

ORCID: https://orcid.org/0000-0002-1508-4812

Faculdade de Odontologia do Recife, Brasil E-mail: Luciano.barreto@for.edu.br

Natália Gomes de Oliveira

ORCID: https://orcid.org/0000-0001-6937-1537

Universidade de Pernambuco, Brasil

E-mail: nataliagomes04@hotmail.com

Marina da Cunha Isaltino

ORCID: https://orcid.org/0000-0002-8991-2721

Faculdade de Odontologia do Recife, Brasil

E-mail: marinaisaltino93@gmail.com

Diogo Cabral de Melo Filho

ORCID: https://orcid.org/0000-0003-4239-109X

Universidade de Pernambuco, Brasil

E-mail: diogo.odonto1@gmail.com

Maria Cecília Souza Pires Gurgel ORCID: https://orcid.org/0000-0002-6462-1696

Universidade de Pernambuco, Brasil

E-mail: mceciliagurgel@gmail.com

Mariana Cecília de Oliveira Terêncio

ORCID: https://orcid.org/0000-0002-2845-6507

Universidade de Pernambuco, Brasil

E-mail: mariana.ceciliaoliveira@upe.br

Marília Fernanda de Andrade Silva Correia

ORCID: https://orcid.org/0000-0001-8527-290X Universidade de Pernambuco, Brasil

E-mail: mariliadeandrade29@gmail.com

Maíra Letícia Ferreira de Santana ORCID: https://orcid.org/0000-0002-2883-2912 Universidade de Pernambuco, Brasil E-mail: maira_leticia@hotmail.com

Iasmin Cirino da Silva

ORCID: https://orcid.org/0000-0001-5939-4524 Universidade de Pernambuco, Brasil E-mail: iasmincirino@gmail.com 


\author{
Izaias Manoel da Silva \\ ORCID: https://orcid.org/0000-0002-9745-2585 \\ Universidade de Pernambuco, Brasil \\ E-mail: izaias.silva@upe.br
}

\begin{abstract}
Resumo
A presença de micro-organismos nos canais são um dos fatores mais relevantes no insucesso do tratamento endodôntico, sendo fundamental seu controle e eliminação. O objetivo do trabalho foi avaliar, in vitro, a atividade antimicrobiana do óleo essencial do alecrim associado ao hidróxido de cálcio, determinando a concentração inibitória mínima (CIM) e concentração bactericida mínima (CBM). Os grupos experimentais foram divididos em 7: CN (controle negativo); CP (controle positivo); CC (controle de crescimento); CE (controle de esterilidade); AL Rosmarinus officinalis; HAL -hidróxido de cálcio e Rosmarinus officinalis; HC - hidróxido de cálcio e água destilada. Após a revitalização das cepas de Enterococcus faecalis (ATCC 14506), os testes para atividade antibacteriana foram realizados por meio da microdiluição em caldo a fim de definir a Concentração Inibitória Mínima (CIM) e a Concentração Bactericida Mínima (CBM). O ensaio foi realizado em triplicata, e as placas de microdiluição foram incubadas em anaerobiose na estufa de $5 \%$ de $\mathrm{CO}_{2}$ à $37^{\circ} \mathrm{C}$ durante 24 horas. Os resultados foram avaliados de forma descritiva e qualitativa. A CIM dos grupos experimentais testados variou de 5,5 a 229,74 mg/ml. Apenas o grupo HAL demonstrou resultado significativo quando comparados aos demais grupos testados, sendo o único resultado encontrado na faixa da CIM de 0 a 100. Pode-se observar que o hidróxido de cálcio não apresentou efetividade contra cepas de E. faecalis, entretanto associado ao óleo essencial de alecrim diminui a CBM e CIM deste, propiciando uma atividade antimicrobiana satisfatória.
\end{abstract}

Palavras-chave: Rosmarinus officinalis; Medicamentos fitoterápicos; Odontologia.

\begin{abstract}
The presence of microorganisms in canals is one of the most relevant factors in the failure of endodontic treatment, being its control and elimination fundamental. The aim of this study was to evaluate, in vitro, the antimicrobial activity of rosemary essential oil associated with calcium hydroxide, determining the minimum inhibitory concentration (MIC) and the minimum bactericidal concentration (MBC). The experimental groups were divided into 7: CN (negative control); CP (positive control); CC (growth control); CE (sterility control); AL - Rosmarinus officinalis; HAL - calcium hydroxide and Rosmarinus officinalis; HC - calcium hydroxide and distilled water. After revitalization of the Enterococcus faecalis strains (ATCC 14506), the tests for antibacterial activity were performed by broth microdilution in order to define the Minimum Inhibitory Concentration (MIC) and the Minimum Bactericidal Concentration (MBC). The assay was performed in triplicate, and the microdilution plates were incubated in anaerobiosis in the $5 \% \mathrm{CO} 2$ oven at $37^{\circ} \mathrm{C}$ for 24 hours. The results were evaluated descriptively and qualitatively. The MIC of the experimental groups tested ranged from 5.5 to $229.74 \mathrm{mg} / \mathrm{ml}$. Only the HAL group showed significant results when compared to the other groups tested, being the only result found in the MIC range of 0 to 100 . It can be observed that calcium hydroxide did not show effectiveness against E. faecalis strains, however, associated with rosemary essential oil, it decreased the BAC and MIC of this, providing a satisfactory antimicrobial activity.
\end{abstract}

Keywords: Rosmarinus officinalis; Phytotherapeutic drugs; Dentistry.

\title{
Resumen
}

La presencia de microorganismos en los conductos es uno de los factores más relevantes en el fracaso del tratamiento endodóntico, siendo fundamental su control y eliminación. El objetivo de este estudio fue evaluar, in vitro, la actividad antimicrobiana del aceite esencial de romero asociado al hidróxido de calcio, determinando la concentración mínima inhibitoria (CIM) y la concentración mínima bactericida (CBM). Los grupos experimentales se dividieron en 7: CN (control negativo); CP (control positivo); CC (control de crecimiento); CE (control de esterilidad); AL Rosmarinus officinalis; HAL - hidróxido de calcio y Rosmarinus officinalis; HC - hidróxido de calcio y agua destilada. Tras la revitalización de las cepas de Enterococcus faecalis (ATCC 14506), se realizaron las pruebas de actividad antibacteriana por microdilución en caldo para definir la Concentración Inhibitoria Mínima (CIM) y la Concentración Bactericida Mínima $(\mathrm{CBM})$. El ensayo se realizó por triplicado y las placas de microdilución se incubaron en anaerobiosis en la estufa al $5 \%$ de $\mathrm{CO} 2$ a $37^{\circ} \mathrm{C}$ durante 24 horas. Los resultados se evaluaron de forma descriptiva y cualitativa. La CIM de los grupos experimentales probados osciló entre 5,5 y 229,74 mg/ml. Sólo el grupo HAL mostró resultados significativos cuando se comparó con los otros grupos probados, siendo el único resultado encontrado en el rango MIC de 0 a 100. Se puede observar que el hidróxido de calcio no mostró eficacia frente a las cepas de E. faecalis, sin embargo, asociado al aceite esencial de romero, disminuyó la CIM y la de éste, proporcionando una actividad antimicrobiana satisfactoria.

Palabras clave: Rosmarinus officinalis; Fármacos fitoterapéuticos; Odontología. 


\section{Introdução}

O objetivo principal do tratamento endodôntico é a limpeza e desinfecção dos canais contaminados e a obturação do sistema em três dimensões, evitando a reinfecção e promovendo a cura da patogênese (Torabinejad et al., 2005). No presente momento as evidências indicam que nenhum instrumento ou técnica é capaz de atuar sobre toda a área de superfície das paredes dentinárias durante o preparo biomecânico (Versiani et al., 2011), resultando sempre na presença de restos de matérias orgânicas e inorgânicas, debris e mesmo de tecido vital em canais laterais, istmos e irregularidades nas paredes (Sasaki et al., 2006; Fornari et al., 2010).

A presença de micro-organismos nos canais são um dos fatores mais relevantes no insucesso do tratamento endodôntico, sendo fundamental seu controle e eliminação, assim como, a neutralização de seus produtos. Durante o preparo químico mecânico os micro-organismos podem permanecer ou invadir o canal e os tecidos periapicais sendo os principais agentes etiológicos das alterações pulpares e periapicais (Aguiar, 2009; Arruda, 2017; Martins, 2017).

A medicação intracanal e solução irrigante possuem relevância no contexto da neutralização do material residual principalmente em casos de infecção persistente e retratamento, os quais contam com a presença de micro-organismos resistentes. O hidróxido de cálcio é o medicamento intracanal de eleição utilizado e seu principal mecanismo de ação é elevar o pH o suficiente para que poucos micro-organismos sobrevivam. Essa medicação apresenta atividade antibacteriana contra a maioria das cepas isoladas de infecções do canal radicular, controle da inflamação, atua como barreira físico-química, solubiliza matéria orgânica, neutraliza produtos tóxicos, controla a exsudação persistente e estimular o reparo por tecido mineralizado. (Law \& Messer, 2004; Siqueira et al., 2010).

Nos últimos anos tem sido observado um crescente interesse da comunidade científica pelas plantas medicinais, por apresentarem potenciais terapêuticos, baixo custo, poucos efeitos adversos quando comparados a medicamentos convencionais e fácil obtenção. (Costa, 2010; Leandro, 2017). O Alecrim (Rosmarinus officinalis) é um exemplo de planta utilizada desde a antiguidade para fins terapêuticos e apresenta propriedade analgésica, espasmolítica, antiinflamatória, antifúngica e possível propriedade antineoplásica. (Alves et al., 2008; Valones, 2008; Costa et al., 2009). Sendo assim, esta pesquisa visa avaliar, in vitro, a atividade antimicrobiana do óleo essencial do Alecrim associado ao hidróxido de cálcio. A hipótese nula testada foi a ausência de diferenças significativas na atividade antimicrobiana entre o hidróxido de cálcio, o óleo essencial e sua associação com o hidróxido de cálcio.

\section{Metodologia}

Trata-se de um estudo experimental in vitro. O presente estudo foi realizado em parceria com o laboratório de cultivo e análise celular (LACEC), todos localizados na Universidade Federal da Paraíba, localizado na cidade de João Pessoa/PB. A medicação intracanal analisada foi o hidróxido de cálcio (Biodinâmica Química e Farmacêutica LTDA, PR, Brasil). O óleo essencial de alecrim (Rosmarinus Officinalis) é vegetal, possui qualidade superior, 100\% puro e natural (FERQUIMA Vargem Grande Paulista - SP) com caracterização conforme a Tabela 1. Um estudo piloto foi desenvolvido a fim de diluir o hidróxido de cálcio no óleo essencial. As diluições foram realizadas com o acréscimo do Tween 80® (Sigma P4780, Steinheim, Germany), o qual atuou como substância ligante. Para facilitar a análise, os grupos foram divididos conforme descrito na Tabela 2. 
Tabela 1: Caracterização dos óleos essenciais usados na pesquisa.

\begin{tabular}{|l|c|c|c|}
\hline ÓLEO & PRINCIPAIS COMPONENTES & DENSIDADE (20 C) & ORIGEM \\
\hline Rosmarinus officinalis & 1,8 cineol (40\%); & 0,919 & Marrocos \\
& $\alpha-$ pineno (13\%); & & \\
& Limoneno (3\%); & & \\
& Cânfora (15\%); & & \\
& Beta pineno (7\%) & & \\
\hline
\end{tabular}

Fonte: Autores.

Tabela 2: Descrição dos grupos e das proporções das medicações intracanais analisados na pesquisa.

\begin{tabular}{|c|c|c|}
\hline GRUPOS & SUBSTÂNCIAS & DOSAGEM \\
\hline CN (controle negativo) & Tween 80® & - \\
\hline CP (controle positivo) & Clorexidina (2\%) & - \\
\hline CE (controle de esterilidade) & Meio de cultura BHI (ágar) & - \\
\hline CC (controle de crescimento) & Meio de cultura BHI (ágar) + bactérias & $7,5 \mathrm{mg}$ \\
\hline HC & Hidróxido de cálcio & $15 \mathrm{~mL}$ \\
\hline AL & Água destilada estéril & - \\
\hline & Rosmarinus officinalis (Alecrim) & $7,5 \mathrm{mg}$ \\
HAL & Hidróxido de cálcio & $11,6 \mathrm{~mL}$ \\
& Rosmarinus Officinalis & $1 \mathrm{~mL}$ \\
& Tween 80® & $2,4 \mathrm{~mL}$ \\
\hline
\end{tabular}

Fonte: Autores.

Para avaliar a atividade antimicrobiana foi utilizado o teste de microdiluição em caldo a fim de mensurar quantitativamente a atividade, in vitro, de agentes com potencial atividade antimicrobiana (NCCLS, 2002, 2003) por meio da CIM e a CBM (Andrews, 2001) das substâncias testadas sobre a cepa de E. faecalis.

As cepas de referência (ATCC - American Type Culture Collection) utilizada para avaliação do potencial antimicrobiano desta pesquisa foi E. faecalis (ATCC 14506) semeadas em Infusão Cérebro Coração (BHI-caldo) (Brain Heart Infunsion Broth - HiMedia Laboratories Pvt Ltd).

Para o cultivo da bactéria foi realizado o descongelamento das cepas de referência em temperatura ambiente. Em seguida, $50 \mu \mathrm{L}$ do inóculo e $5 \mathrm{~mL}(5000 \mu \mathrm{L})$ do meio BHI-caldo foram colocados em tubos falcon com tampa previamente esterilizados. Após homogeneização no vórtex $\left(\right.$ FANEM $\left.^{\circledR}\right)$, os tubos semi-abertos foram colocados em jarra de anaerobiose e levado para a estufa bacteriológica (STERILIFER), durante $48 \mathrm{~h}$ a $37^{\circ} \mathrm{C}$. Após $48 \mathrm{~h}$ do cultivo, o tubo foi colocado em aparelho centrifugador (CENTRIBIO) e centrifugado por 15 minutos na velocidade $2.500 \mathrm{rpm}$. Em seguida, o sobrenadante foi descartado e ao tubo foi acrescentado $5 \mathrm{~mL}$ de solução salina ( $\mathrm{NaCl}$ 0,9\%). Após a mistura foi homogeneizada no vórtex e realizada a leitura da densidade bacteriana (NCCLS, 2003).

A suspensão bacteriana preparada em solução salina $(\mathrm{NaCl} 0,9 \%)$ foi padronizada através de espectrofotômetro (GLOMAX MULTI, Promega) emitindo comprimento de onda de $625 \mathrm{~nm}$ e valor de absorbância variando entre 0,080 a 0,100 correspondente a concentração de 1 a $2 \times 10^{8} \mathrm{UFC} / \mathrm{mL}$, equivalente a 0,5 da Escala de MacFarland. Para a leitura, uma placa de 96 poços de fundo chato $\left(\operatorname{COSTAR}^{\circledR}\right.$ ) foi utilizada, onde no primeiro poço foram colocados $100 \mu \mathrm{L}$ de salina e no segundo poço, $100 \mu \mathrm{L}$ do inóculo previamente preparado (NCCLS, 2003).

A CIM impede o crescimento visível de um micro-organismo no teste de sensibilidade por diluição em ágar ou caldo. Este método é usado para determinar a concentração mínima de um agente a fim de inibir sua reprodução ou eliminar microorganismos. A CIM bactericida provoca a morte dos micro-organismos. A CIM bacteriostática inibe a reprodução bacteriana não provocando a morte dos mesmos. Já a CBM é um método que avalia a menor concentração da droga que inibe pelo menos $99,9 \%$ do inóculo bacteriano. 
Os controles de viabilidade da cepa foram: controle de crescimento (CC - $100 \mu \mathrm{L}$ do meio e $100 \mu \mathrm{L}$ do inóculo),

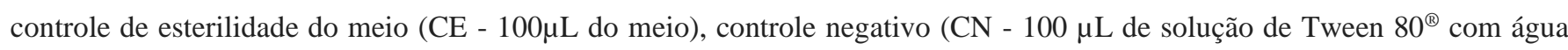
destilada e $100 \mu \mathrm{L}$ de meio) com o intuito de verificar se há ou não interferência sobre a biologia dos micro-organismos e controle positivo (CP - $100 \mu \mathrm{L}$ de meio com $100 \mu \mathrm{L}$ da solução de Digluconato de Clorexidina e $100 \mu \mathrm{L}$ do inóculo).

Inicialmente, foram distribuídos $100 \mu \mathrm{L}$ de meio BHI nos orifícios da placa de microdiluição de fundo em $\mathrm{U}$. Posteriormente, $100 \mu \mathrm{L}$ da substância testada foi transferida para o primeiro poço e diluídos seriadamente a partir da retirada de uma alíquota de $100 \mu \mathrm{L}$ da cavidade mais concentrada para a cavidade sucessora, seguindo até o ultimo poço. Em seguida, foram adicionados a cada poço $100 \mu \mathrm{L}$ do inóculo na concentração $5 \times 10^{5} \mathrm{UFC} / \mathrm{mL}$ (NCCLS, 2003). O ensaio foi realizado em triplicata, e as placas de microdiluição foram incubadas em estufa a $37^{\circ} \mathrm{C}$ durante 24 horas.

A leitura para determinação da CIM sobre a cepa testada foi realizada pelo método visual, levando em consideração a formação ou não de aglomerados de bactérias no fundo da cavidade da placa de microdiluição (NCCLS, 2003). Dessa forma, a CIM foi considerada a menor concentração do produto em teste capaz de inibir o crescimento das cepas utilizadas nos ensaios microbiológicos (Andrews, 2001).

Para a confirmação do resultado visual, ou seja, para confirmar a presença de micro-organismos viáveis nas concentrações inibitórias, $30 \mu \mathrm{L}$ do corante Resazurina Sódica (Sigma ${ }^{\circledR}$ ) foram adicionados como indicador de óxido-redução, o qual indica alteração de pH devido à presença de micro-organismos (Montejano et al., 2005). Após 1 hora da aplicação do corante na placa, cada poço foi avaliado e tabulado os resultados.

As CBMs das substâncias testadas e do controle positivo foram determinadas a partir do resultado da CIM, onde foi realizado o subcultivo de $10 \mu \mathrm{L}$ da concentração correspondente à inibitória e as concentrações imediatamente mais concentradas (CIM x 2 e CIM x 4) (De Castro \& Lima, 2013) em placas de petri contendo meio sólido (BHI-ágar). Após 48h de incubação à $37^{\circ} \mathrm{C}$, foi realizada a leitura da $\mathrm{CBM}$, considerada a menor concentração que impediu o crescimento visível do subcultivo (Andrews, 2001).

Os dados foram tabulados em planilha Excel e calculados conforme o Manual Analítico Bacteriológico (Food and Drug Admnistration, 2001). Os resultados foram avaliados de forma descritiva e qualitativa.

\section{Resultados}

A CIM e CBM dos 7 grupos experimentais estão apresentados na Tabela 3. A CIM dos óleos essenciais variou de 5,5 a 229,74 mg/ml. Apenas o grupo HAL demonstrou resultado significativo quando comparados aos demais grupos testados, sendo o único resultado encontrado na faixa da CIM de 0 a 100.

$\mathrm{O}$ uso da placa de Petri para plaqueamento foi realizado para cada grupo experimental a fim de determinar a CBM. Os grupos controle positivo e de esterilidade não apresentaram crescimento bacteriano nas placas de Petri (Figuras 1 e 2). Isso demonstra que o uso da clorexidina (2\%) é eficaz contra cepas de E. faecalis e não houve contaminação do BHI ágar durante o desenvolvimento da pesquisa. Os grupos negativos e de crescimento retrata crescimento bacteriano nas placas de Petri (Figuras 1 e 2) conforme os objetivos esperados desses grupos. Os grupos AL e HAL não apresentaram crescimento bacteriano nas placas de Petri, diferentemente do grupo HC que não apresentou efetividade (Figuras 3 e 4).

A presença do Tween $80 \circledR$ nas diluições não teve impacto sobre a atividade antibacteriana dos óleos essenciais. A CIM e CBM do grupo $\mathrm{Ca}(\mathrm{OH})_{2}$ não pode ser determinada porque em nenhuma concentração inibição de crescimento bacteriano. 
Research, Society and Development, v. 10, n. 16, e522101623865, 2021

(CC BY 4.0) | ISSN 2525-3409 | DOI: http://dx.doi.org/10.33448/rsd-v10i16.23865

Tabela 3: CIM e CBM dos grupos experimentais em cepas de E. faecalis ATCC 14506.

\begin{tabular}{lll}
\hline GRUPO & $\begin{array}{l}\text { CIM } \\
(\mathrm{mg} / \mathrm{ml})\end{array}$ & $\begin{array}{l}\text { CBM } \\
(\mathrm{mg} / \mathrm{ml})\end{array}$ \\
\hline CP & Efetivo & Efetivo \\
CN & $\mathrm{ne}^{*}$ & $\mathrm{ne}^{*}$ \\
$\mathrm{CE}$ & $\mathrm{a}$ & $\mathrm{a}$ \\
$\mathrm{CC}$ & $\mathrm{b}$ & $\mathrm{b}$ \\
$\mathrm{HC}$ & $\mathrm{ne}$ & $\mathrm{ne}$ \\
$\mathrm{AL}$ & 114,87 & 229,74 \\
HAL & 5,55 & 5,55 \\
\hline
\end{tabular}

*ne = não efetivo; $\mathrm{a}=$ sem presença de bactérias; $\mathrm{b}=$ presença de bactérias. Fonte: Autores.

Figura 1 - Concentração bactericida mínima (CBM) de E. faecalis ATCC 14506 para (a) controle negativo e (b) controle positivo avaliados após $24 \mathrm{~h}$ de subcultivo em BHI ágar.

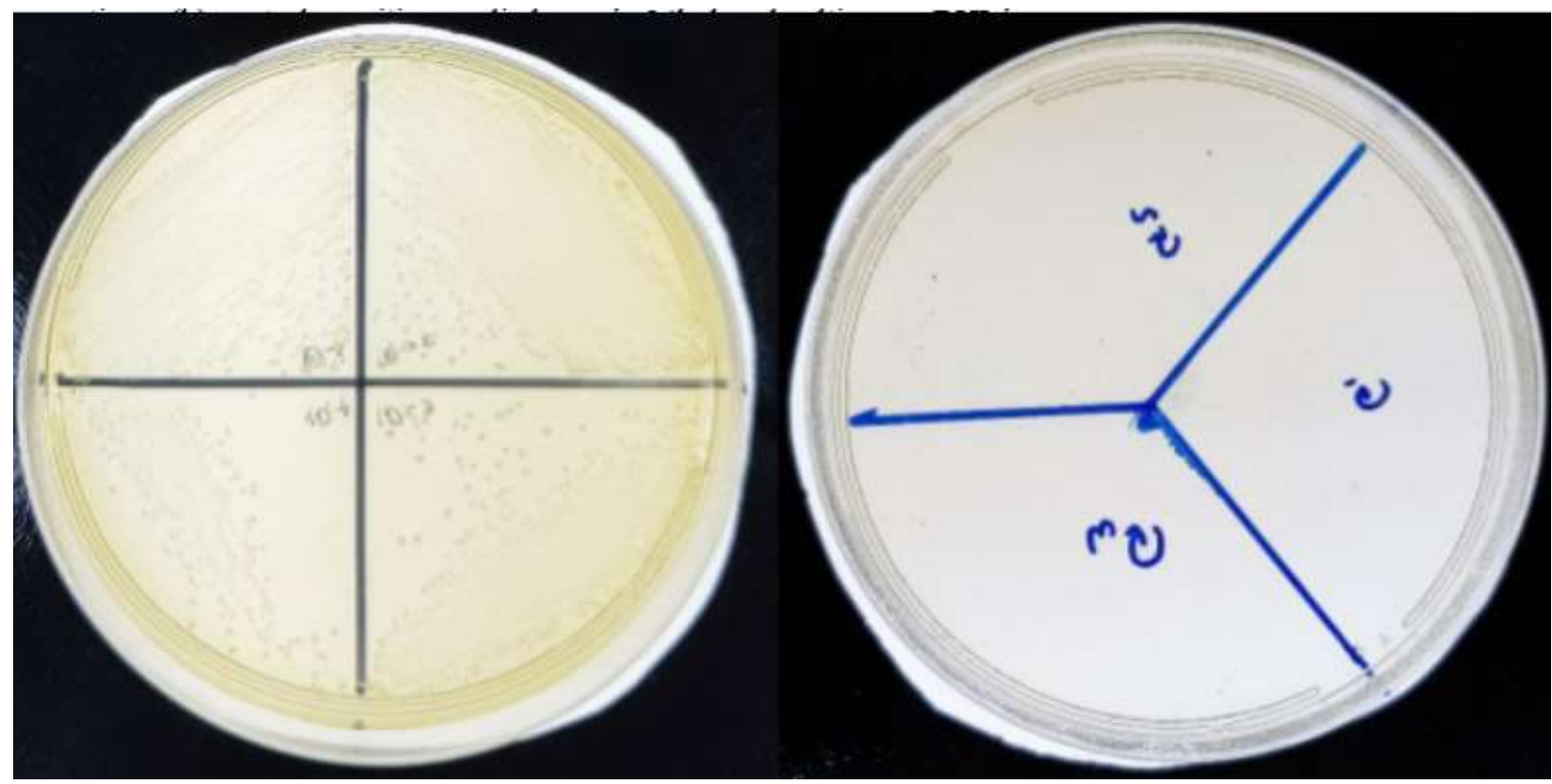

Fonte: Autores. 
Figura 2 - Concentração bactericida mínima (CBM) de E. faecalis ATCC 14506 para (a) controle de crescimento e (b) controle de esterilidade avaliados após 24 h de subcultivo em BHI ágar.

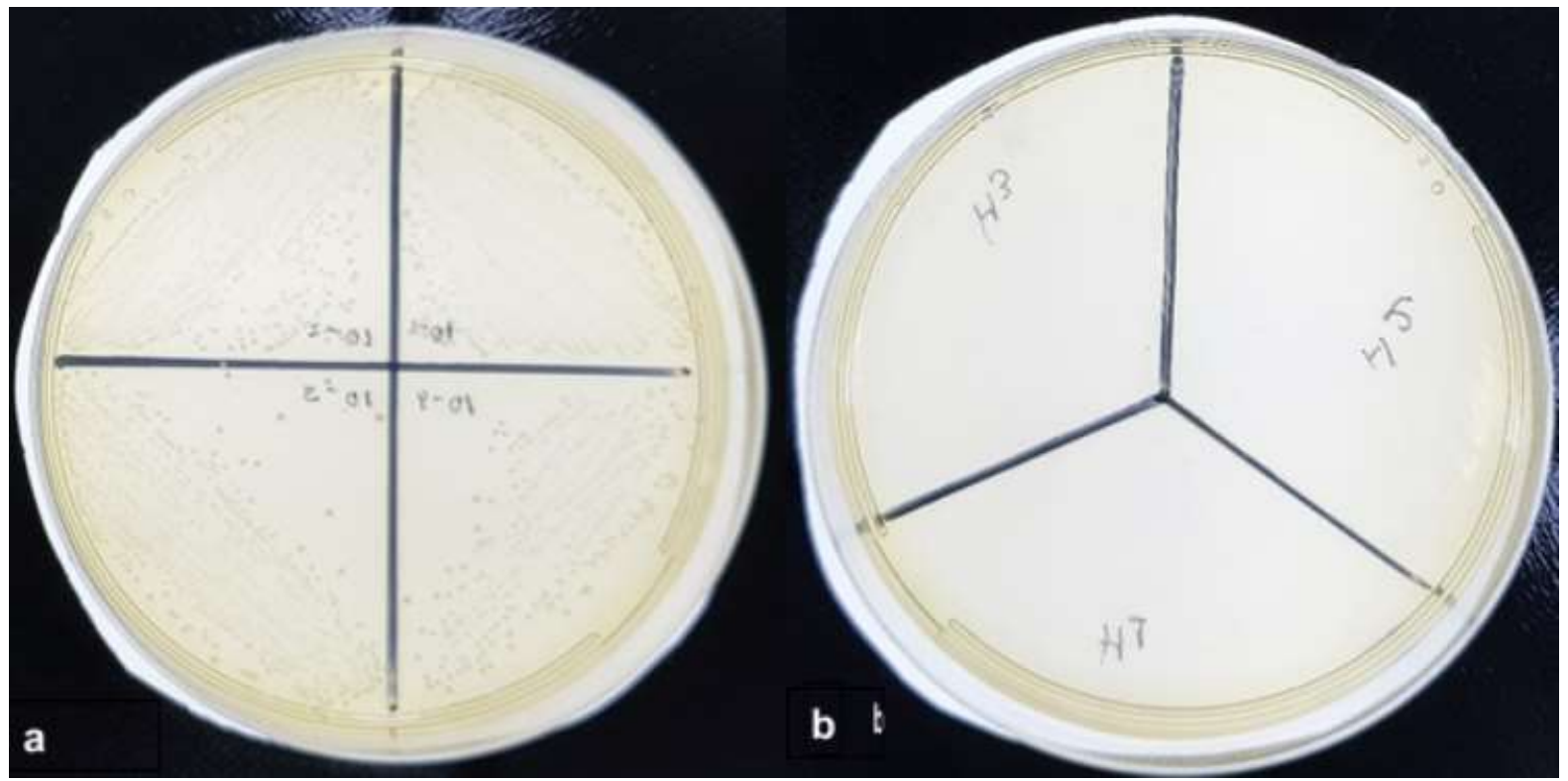

Fonte: Autores.

Figura 3 - Concentração bactericida mínima (CBM) de E. faecalis ATCC 14506 para (a) grupo AL e (b) grupo HAL avaliados após $24 \mathrm{~h}$ de subcultivo em BHI ágar.

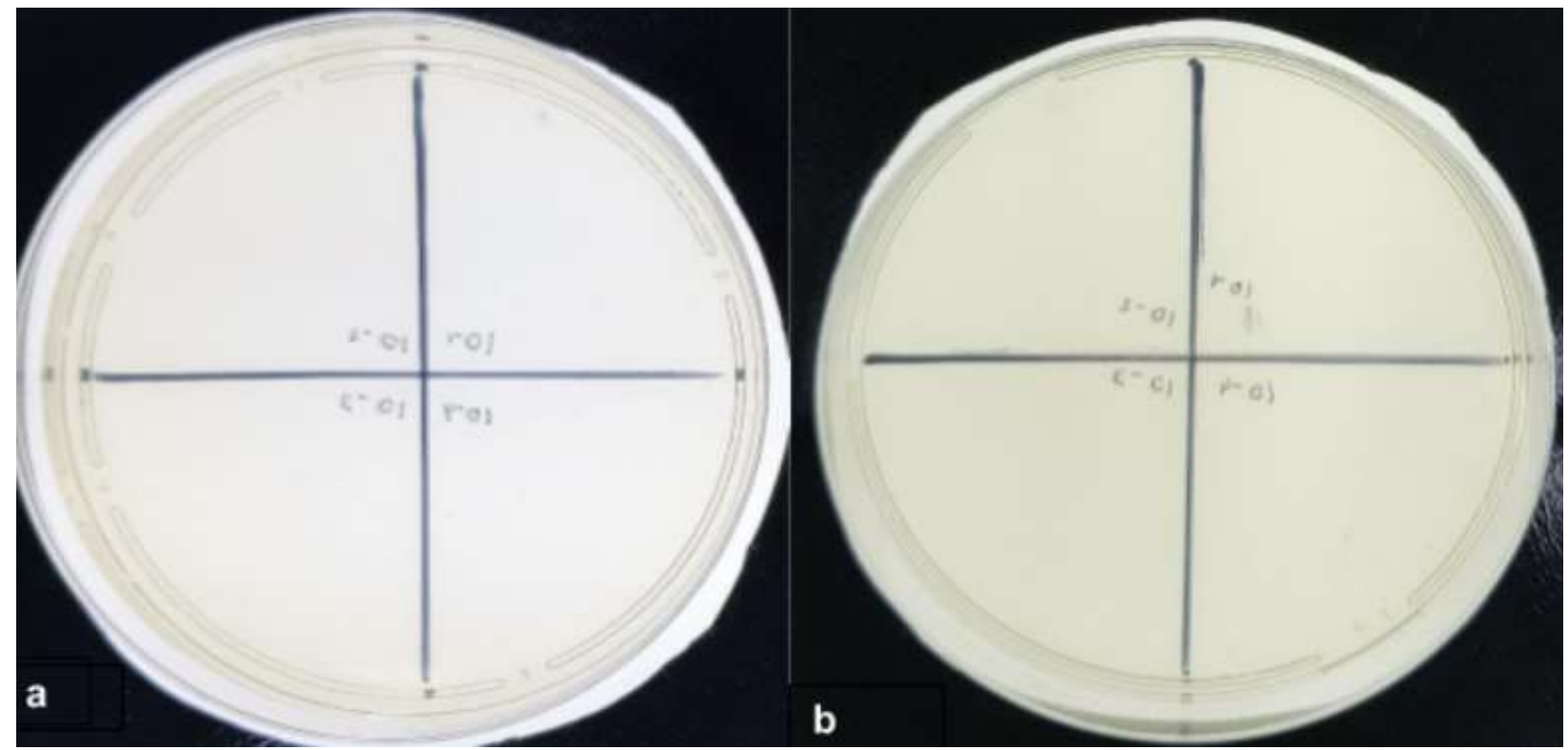

Fonte: Autores. 
Figura 4 - Concentração bactericida mínima (CBM) de E. faecalis ATCC 14506 para grupo HC avaliado após 24h de subcultivo em BHI ágar.

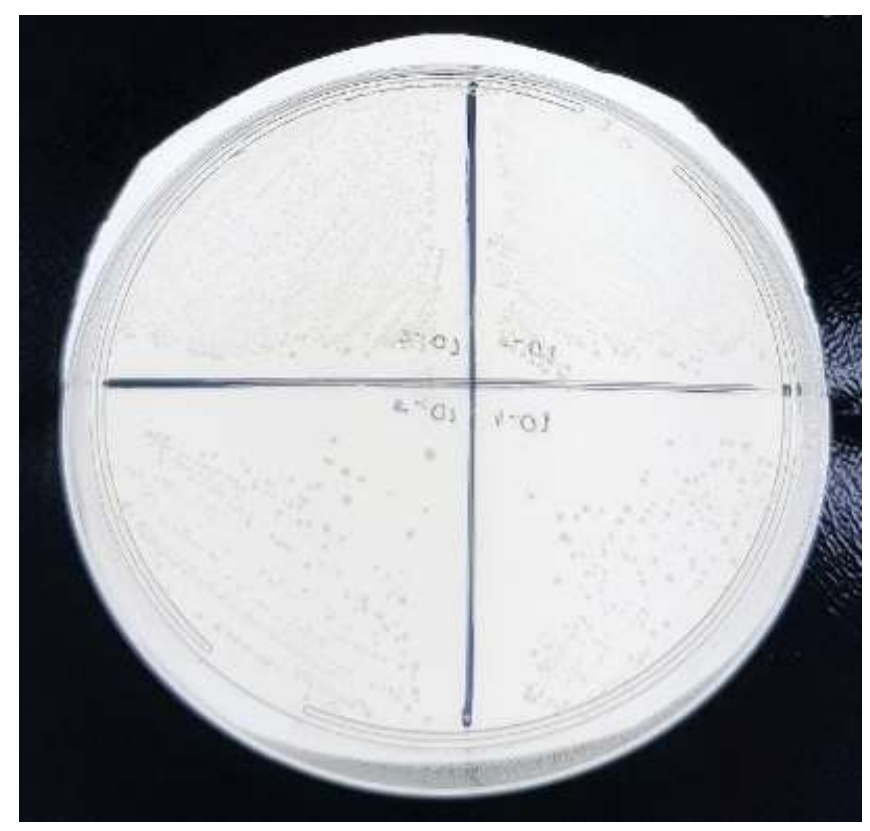

Fonte: Autores.

\section{Discussão}

Este trabalho avaliou, in vitro, a atividade antimicrobiana do óleo essencial de alecrim associado a medicamento de uso endodôntico padrão, determinando a CIM e a CBM contra cepa de E. faecalis, a qual é prevalente nas infecções endodônticas (Mayer, 2017). Os produtos de origem vegetal são interessantes para a odontologia por apresentarem um variado potencial terapêutico, baixo custo e fácil obtenção. (Teixeira, 2012). Os óleos essenciais apresentam atividade contra uma ampla variedade de micro-organismos: vírus, fungos, protozoários e bactérias. (Probst, 2012).

O E. faecalis apresenta resistência ao hidróxido de cálcio, corroborando com os nossos achados, pois este microorganismo pode invadir e adaptar-se perfeitamente bem nos túbulos dentinários e sobreviver no meio necrótico pulpar, onde os suprimentos de sangue e oxigênio são limitados ou inexistentes, resistindo à antibioticoterapia, às medicações intracanais padrões utilizadas atualmente e também ao preparo químico-mecânico resultando em insucessos endodônticos (Silva et al., 2013; Lemos et al., 2015). A adesão ao colágeno possibilita sua sobrevivência, crescimento e reinfecção, apresentando habilidade em adaptar-se às severas condições ambientais, além de apresentar enzimas líticas, citolisinas, substância de agregação e ácido lipoteicoico contribuem para a sua grande virulência. (Freire et al., 2017; Sousa, 2017).

Estudos demonstraram a importância da medicação intracanal entre sessões para eliminar micro-organismos que sobreviveram à etapa de preparo químico-mecânico. (Delegado et al., 2005). Estudos relataram a variação da suscetibilidade de micro-organismos individuais às pastas de hidróxido de cálcio. Todas as seis bactérias anaeróbias facultativas e quatro anaeróbios gram-negativos foram mais suscetíveis ao hidróxido de cálcio preparado com veículos oleosos concluindo que a habilidade de difusão e atividade antimicrobiana do hidróxido de cálcio estão relacionadas com os tipos de veículos utilizados, dentre as bactérias testadas, o E. faecalis apresentou maior resistência. No presente estudo, o hidróxido de cálcio com a água destilada não apresentou efetividade contra cepas de E. faecalis, no entanto, quando associado a um veículo oleoso, como o óleo essencial de alecim, apresentou efetividade com CIM e CBM iguais com valor de 5,55 mg/ml, podendo ocorrer sinergismo. (Gomes et al., 2002) 
O óleo essencial de alecrim apresenta potencial anti-inflamatório, analgésico e antimicrobiano com atividade antifúngica e inibitória sobre o crescimento de bactérias gram-negativas, e principalmente, gram-positivas. (Alves et al., 2008; Valones, 2008; Costa et al., 2009; Probst, 2012). Autores acreditam que os compostos responsáveis pela atividade antimicrobiana do alecrim são os núcleos aromáticos, por conter um grupo funcional polar (Porte e Godoy, 2001). Outros autores acreditam que essa atividade se deve a grande quantidade de compostos fenólicos, a ação do ácido carnósico e do carnasol. (Moreno et al., 2006).

As variações na composição química do óleo essencial de alecrim são dependentes de fatores como: região de cultivo, metodologia de extração e análise, parte da planta utilizada e preparo da matéria prima para a extração (seca ou in natura). Estes fatores podem auxiliar na justificativa da variação dos resultados encontrados dos estudos citados, sendo primordial que a composição do óleo essencial de alecrim utilizada seja conhecida, pois, as alterações de composição química podem modificar o teor do princípio ativo presente no óleo (Castro \& Ferreira, 2012).

O extrato hidroalcoólico de folhas de $R$. officinalis levou a resultados satisfatórios para as bactérias E. faecalis (ATCC 29212), e seus isolados clínicos, com valores de CIM variando entre 40 a $400 \mu \mathrm{g} / \mathrm{mL}$ e CBM de 100 a $300 \mu \mathrm{g} / \mathrm{mL}$. (Petrolini et al., 2013) Outro estudo utilizou tinturas hidroalcoólicas de alecrim obtidas através de uma farmácia de manipulação e diluídas em proporções de 1:1 (forma pura) até 1:64 em álcool a 70\%, encontrando uma CIM de 14,06 mg/mL (Ferreira filho et al., 2015). No presente estudo o óleo essencial de alecrim foi adquirido comercialmente e apresentaram CIM 114,87 e CBM 229,74. também utilizaram extratos de alecrim adquiridos comercialmente e encontraram uma de CIM $50 \mathrm{mg} / \mathrm{mL}$ de contra o E. faecalis. Essas discordâncias nos valores da CIM e CBM podem ser devido às diversas formas de preparo dos substratos da planta. (Oliveira et al., 2017)

Diante de poucos estudos na literatura acerca da atividade antimicrobiana $R$. officinalis contra o $E$. faecalis observamos outros resultados com outras bactérias. Onde o extrato de $R$. officinalis foi efetivo na inibição de aderência de $S$. mitis ATCC 98811, S. mutans ATCC 25175 e S. sobrinus ATCC 27609. (Silva et al., 2008) Em outro estudo relataram a efetividade do alecrim contra S. mitis, S. mutans, S. sanguis, S. sobrinus e Lactobacillus casei. (Alves et al., 2008) Estudos demonstram a efetividade do alecrim contra Klebsiella pneumoniae, Enterobacter aerogenes, Serratia marcescens, $S$. pyogenes, Proteus mirabilis, Bacillus subtilis, Escherichia coli, Proteus vulgaris, Staphylococcus aureus e Pseudomonas aeruginosa. (Sousa et al., 2017) Os resultados obtidos utilizando a folha do alecrim confirmam a alta sensibilidade das bactérias Gram-positivas ao alecrim, entretanto, ainda existe divergências de resultados na literatura necessitando de mais estudos. (Porte \& Godoy, 2001)

\section{Conclusão}

Neste estudo, pode-se observar que o hidróxido de cálcio não apresentou efetividade contra cepas de E. faecalis, entretanto associado ao óleo essencial de alecrim diminui a CBM e CIM deste, propiciando uma atividade antimicrobiana satisfatória.

\section{Referências}

Abinader, C. D. (2005). Avaliação in vitro da atividade antimicrobiana da pasta de hidróxido de cálcio associada a diferentes veículos frente a Candida albicans e ao Enterococcus faecalis. Manaus, 143p. Dissertação de Mestrado em Patologia Tropical-Faculdade de Ciências da Saúde, Universidade Federal do Amazonas.

Aguiar, A. P. S., Caires, L. P., Maekawa, L. E., Valera, M. C., \& Koga-Ito, C. Y. (2017). Avaliação in vitro da ação do extrato glicólico de gengibre sobre Candida albicans. Revista de Odontologia da Universidade Cidade de São Paulo, 21(2), 144-149.

Alves, P. M., Pereira, J. V., Higino, J. S., Pereira, M. D. S. V., \& Queiroz, L. M. G. (2008). Atividade antimicrobiana e antiaderente in vitro do extrato de rosmarinus officinalis linn.(alecrim) sobre microrganismos cariogênicos. Arquivos em Odontologia, 44(2). 
Andrews, JM (2001). Determinação das concentrações inibitórias mínimas. Journal of antimicrobial Chemotherapy , 48 (suppl_1), 5 -16.

Arruda, E. D. S. (2017). Estudo in vitro de um protocolo de retratamento endodôntico realizado com o Sistema Protaper Next em molares inferiores.

Bouyahya, A., Et-Touys, A., Bakri, Y., Talbaui, A., Fellah, H., Abrini, J., \& Dakka, N. (2017). Composição química dos óleos essenciais de Mentha pulegium e Rosmarinus officinalis e suas atividades antileishmania, antibacteriana e antioxidante. Microbial pathogenesis , 111 , $41-49$.

Brito-Júnior, M., Nobre, SA, Freitas, JC, Camilo, CC, \& Faria-e-Silva, AL (2012). Atividade antibacteriana de um extrato de planta e seu potencial para desinfetar cones de guta-percha. Acta odontologica latinoamericana: AOL, 25 (1), 9-13.

de Castro Guimarães, C., Ferreira, T. C., de Oliveira, R. C. F., Simioni, P. U., \& Ugrinovich, L. A. (2017). Atividade antimicrobiana in vitro do extrato aquoso e do óleo essencial do alecrim (Rosmarinus officinalis L.) e do cravo-da-índia (Caryophyllus aromaticus L.) frente a cepas de Staphylococcus aureus e Escherichia coli. Revista Brasileira de Biociências, 15(2).

Costa, A. C. B. P. D., Pereira, C. A., Freire, F., Junqueira, J. C., \& Jorge, A. O. C. (2013). Atividade antifúngica dos extratos glicólicos de Rosmarinus officinalis Linn. e Syzygium cumini Linn. sobre cepas clínicas de Candida albicans, Candida glabrata e Candida tropicalis. Revista de Odontologia da UNESP, 38(2), 111-116.

Costa, E. M. M. D. B., Barbosa, A. S., Arruda, T. A. D., Oliveira, P. T. D., Dametto, F. R., Carvalho, R. A. D., \& Melo, M. D. D. (2010). Estudo in vitro da ação antimicrobiana de extratos de plantas contra Enterococcus faecalis. Jornal Brasileiro de Patologia e Medicina Laboratorial, 46, $175-180$.

Castro, R. D. D., \& Lima, E. O. (2013). Atividade anti-cândida e composição química do óleo essencial de Cinnamomum zeylanicum blume. Arquivos Brasileiros de Biologia e Tecnologia,

Delgado, R. J., Gasparoto, T. H., Sipert, C. R., Pinheiro, C. R., Moraes, I. G., Garcia, R. B., \& Bernardineli, N. (2010). Efeitos antimicrobianos do hidróxido de cálcio e clorexidina em Enterococcus faecalis. Journal of endodontics, 36 (8), 1389-1393.

Faria, L. R. D. D. (2005). Validação farmacológica do óleo essencial de Rosmarinus officinalis L.(alecrim): atividades antiinflamatória e analgésica.

Ferreira Filho, J. C. C., Ribeiro, I. L. A., Martins, J. M., Borges, L. P., \& Valença, A. M. G. (2015). Ação antibacteriana de Rosmarinus officinalis L. e Maytenus ilicifolia Mart. sobre bactérias orais. Revista da Faculdade de Odontologia-UPF, 20(3)

Fornari, V. J., Silva - Sousa, Y. T. C., Vanni, J. R., Pécora, J. D., Versiani, M. A., \& Sousa - Neto, M. D. (2010). Avaliação histológica da eficácia do aumento do alargamento apical para a limpeza do terço apical de canais curvos. International Endodontic Journal, 43 (11), $988-994$.

Freire, G. E., Aguiar, B. A., Veras, M. D. O. V., Ferreira, A. C., Martins, C. D. S., Costa, D. V. D. S., \& Almeida-Gomes, F. (2017). Avaliação in vitro de diferentes agentes de descontaminação de cones de guta-percha.

Gomes, B. P. F. D. A., Ferraz, C. C. R., Vianna, M. E., Rosalen, P. L., Zaia, A. A., Teixeira, F. B., \& Souza-Filho, F. J. D. (2002). Atividade antimicrobiana in vitro de pastas de hidróxido de cálcio e seus veículos contra microrganismos selecionados. Revista odontológica brasileira, $13,155-161$.

Law, A., \& Messer, H. (2004). Uma análise baseada em evidências da eficácia antibacteriana de medicamentos intracanal. Journal of endodontics , 30 (10), 689-694.

da Silva Leandro, Y. A., Jardim, I. N., \& Gavilanes, M. L. (2017). Uso de plantas medicinais nos cuidados de saúde dos moradores de assentamento no município de Anapu, Pará, Brasil. Biodiversidade, 16(2).

Lemos, M. G., Ceretta, L. B., Simões, P. W., \& Crema, M. M. (2017). Eficácia do hidróxido de cálcio associado a veículos medicamentosos no combate ao enterococcus faecalis no interior do canal radicular: uma revisão de literatura. Revista de Odontologia da Universidade Cidade de São Paulo, 27(2), 135-141.

Martins, A. M. (2017). Indicações e Contra-Indicações do Retratamento Endodôntico: Revisão de Literatura.

Mayer, J. D. S. L. (2017). Ação antibacteriana do extrato de Spondias mombin L. frente ao Enterococcus faecalis (Bachelor's thesis, Universidade Federal do Rio Grande do Norte).

Montejano, H. A., Gervaldo, M., \& Bertolotti, S. G. (2005). A extinção de estados excitados de resazurina e resorufina por p-benzoquinonas em solventes polares. Corantes e Pigmentos, 64 (2), 117-124.

Moreno, S., Scheyer, T., Romano, C. S, \& Vojnov, A. A (2006). Atividades antioxidante e antimicrobiana dos extratos de alecrim associadas à sua composição polifenólica. Pesquisa de radicais livres, 40 (2), 223-231.

Aprovada, N. Método de Referência para Testes de Diluição em Caldo para a Determinação da Sensibilidade a Terapia Antifúngica dos Fungos Filamentosos.

Oliveira, E. P. M. D., Irala, L. E. D., Santos, A. R. D., \& Melo, T. A. F. D. (2010). Avaliação da ação antimicrobiana de quatro formulações a base de hidróxido de cálcio utilizadas como medicação intracanal. RFO UPF, 15(1), 35-39.

Pereira, R. F. L., da Silva Pedrosa, M., \& Delboni, M. G. (2017). Terapia fotodinâmica em canais infectados com Enterococcus faecalis: revisão de literatura. Revista da Faculdade de Odontologia-UPF, 22(2).

Petrolini, F. V. B., Lucarini, R., Souza, M. G. M. D., Pires, R. H., Cunha, W. R., \& Martins, C. H. G. (2013). Avaliação do potencial antibacteriano de Petroselinum crispum e Rosmarinus officinalis contra bactérias causadoras de infecções do trato urinário. Brazilian Journal of Microbiology , 44 (3), 829-834.

Pia, A. A., \& Silva, A. L. D. (2018). A eficiência do hidróxido de cálcio como medicação intracanal no tratamento endodôntico.

Porte, A., \& Godoy, R. L. D. O. (2001). Alecrim (Rosmarinus officinalis L.): propriedades antimicrobiana e química do óleo essencial. Boletim do Centro de Pesquisa de Processamento de Alimentos, 19(2). 
Research, Society and Development, v. 10, n. 16, e522101623865, 2021

(CC BY 4.0) | ISSN 2525-3409 | DOI: http://dx.doi.org/10.33448/rsd-v10i16.23865

Probst, I. D. S. (2012). Atividade antibacteriana de óleos essenciais e avaliação de potencial sinergético.

Sasaki, E. W., Versiani, M. A., Perez, D. E. D. C., Sousa-Neto, M. D., Silva-Sousa, Y. T., \& Silva, R. G. (2006). Análise ex vivo dos detritos remanescentes em canais radiculares achatados de dentes vitais e não vitais após preparo biomecânico com instrumentos rotativos de Ni-Ti. Revista odontológica brasileira, 17, 233-236.

Silva, M. D. S. A., Silva, M. A. R., Higino, J. S., Pereira, M. S. V., \& Carvalho, A. D. A. (2008). Atividade antimicrobiana e antiaderente in vitro do extrato de Rosmarinus officinalis Linn. sobre bactérias orais planctônicas. Revista Brasileira de Farmacognosia, 18, 236-240.

Silva, M. B. (2011). Avaliação in vitro da atividade antimicrobiana de pastas endodônticas à base de extrato glicólico de Musa paradisiaca frente a Enterococcus faecalis.

Siqueira Jr, J. F., Alves, F. R., Almeida, B. M., de Oliveira, J. C. M., \& Rôças, I. N. (2010). Capacidade de preparação quimiomecânica com instrumentos rotativos ou lima autoajustável para desinfetar canais radiculares de formato oval. Journal of endodontics, 36 (11), $1860-1865$.

de Sousa, M. N., de Macedo, A. T., \& dos Santos, J. R. A. (2017). Inter-relação entre Enterococcus faecalis, Candida albicans e os tratamentos endodônticos. Revista de Investigação Biomédica, 9(1), 49-57.

de Sousa, R. R. F., da Silva, M. R., \& Siliano, P. R. (2017). Análise de eficácia antimicrobiana de extratos vegetais de Rosmarinus officinalis L., Salvia officinalis L. e Coriandrum sativum L. Unisanta BioScience, 6(3), 207-214.

Sundqvist, G., Figdor, D., Persson, S., \& Sjögren, U. (1998). Análise microbiológica de dentes com falha no tratamento endodôntico e o resultado do retratamento conservador. Oral Surgery, Oral Medicine, Oral Pathology, Oral Radiology, and Endodontology, 85 (1), 86-93.

Teixeira, L. (2012). Avaliação do uso do Extrato de Alecrim de Jardim (Rosmarinus officinalis Linn) no controle do Biofilme Dental. Trabalho de Conclusão de Curso. Curso de Odontologia. Universidade Federal do Paraná. Curitiba/PR.

Torabinejad, M., Kutsenko, D., Machnick, T. K.., Ismail, A., \& Newton, C. W (2005). Níveis de evidência para o resultado do tratamento endodôntico não cirúrgico. Journal of endodontics, 31 (9), 637-646.

Versiani, M. A., Pécora, J. D., \& de Sousa-Neto, M. D. (2011). Preparo de canal radicular plano-ovalado com instrumento de lima autoajustável: um estudo por micro tomografia computadorizada. Journal of endodontics, 37 (7), 1002-1007.

Valones, M. A. A. (2008). Avaliação da atividade antimicrobiana in vitro do dentifrício à base do extrato alcoólico de Rosmarinus Officinalis Linn. (ALECRIM) sobre cepas padrão de S. mutans, S. aureus e L. casei (Master's thesis, Universidade Federal de Pernambuco).

Zamin, C. (2017). Aplicação de óleos essenciais como solução irrigadora em canais radiculares e túbulos dentinários infectados com Enterococcus faecalis e Candida albicans. 